\title{
Making Conceptual Knowledge Connections to Clear Misconceptions in Fractions in Primary Classrooms
}

\author{
Mithu Pal \\ Institute of Advanced Studies in Education \\ Jamia Milia Islamia University, New Delhi
}

\begin{abstract}
This study aimed at investigating the effect of making conceptual knowledge connections through multiple representations in clearing misconceptions in the study of fractions. The study used a quasiexperimental research design with a pre-test- intervention- post-test format where in 40 students of Grade 4 of a primary school in New Delhi were randomly selected. The students in the control group were taught fractions using the conventional approach where as the experimental group was exposed to an instructional program that utilized a problem solving approach. The emphasis during the intervention program was on making connections among various mathematical representations to develop fraction number sense and operation sense among children. The treatment group was immersed in fraction instructions for six weeks and problem contexts were used each and every day to clear misconceptions. The effect of making conceptual knowledge connections in fractions and the performance of the students in solving fraction problems were assessed with a pre-test and post-test. For better understanding of the thinking processes and working patterns of the children while dealing with fractions, the classes were regularly observed by the researcher and interviews with 5 students each in the control and experimental groups were conducted by her. The findings of the study indicated that the students who received the treatment had significantly higher scores, used manipulatives more meaningfully when posed with fraction problems and had lesser misconceptions suggesting deeper conceptual understanding of fractions. Keywords: Fractions, Multiple Representations, Instructional Program, Problem Solving, Conceptual Understanding, Misconceptions
\end{abstract}

\section{Introduction}

Fractions are an integral part of elementary and middle school curriculum and their importance runs into the high school mathematics curricula as well. But in spite of the significant role that fractions play in the mathematics curriculum and the increased time that teachers spend teaching this concept, there are many difficulties and misconceptions that abound and surround this important topic of fractions.

Many children's difficulties actually start with the introduction of fractions. The reason for that may be manifold. According to National Council of Educational Research and Technology(NCERT, 2008), many of the whole numbers may get wrongly applied in the case of fractions - for instance a child reasoning $1 / 2$ is less than $1 / 3$ because 2 is less than 3 . Also compared to whole numbers, students spend very little time on the fundamental concepts of fractions often moving too quickly onto learning for operations and their properties. A third reason for students' difficulties particularly in the case of common fractions - is the propensity that books and teachers have towards computations and other work with 'bigger' fractions which have no bearing on the child's life. In fact, hardly any of us would have done such calculations in real life or felt the need for them except in the mathematics class! All these hurdles together hinder the child's understanding of fractions.

Canterbury (2007) indicates, on the basis of findings from different studies that most of the students' difficulties with understanding fraction concepts result due to traditional fraction instruction and that the researchers believe that to remove such difficulties, those instructional approaches are needed that emphasize conceptual instead of procedural knowledge. Hitt (2001) stated that mathematics facilitators at almost all levels focus mainly on the use of algebraic system of representations and tend to leave aside other representations like geometric or intuitive, the reason being that the algebraic system of representing fractions is formal and the others are not. Thus complex concepts like fractions get linked to restricted representations only, while teaching.

Students of a well to do private school in South Delhi were posed with the question "What is a fraction?" One of the most common answers that came up, unfortunately was "A line with a number below and under it." Rather than associating fractions as being some quantity in everyday life that can be represented mathematically using symbols, the line and the placement of the numbers dominated the answers.

\subsection{Conceptual Knowledge Connections}

Conceptual elaboration and understanding of fractions for a primary school student would mean understanding the multiple meaning of fractions. This would involve a basic understanding of the nature of fractions with a perspective on it many meanings. This means not limiting a child to 'part of a whole' meaning 
of fractions but an introduction to other ideas - like fractions as part of a collection, fraction as division operation, fraction for comparison and also fraction to be seen as a number. The connection between real-world experiences and symbols is essential in enabling students with the power to make sense of fractions. Other conceptual knowledge connections needed by students to develop number sense and operation sense of fraction include connections among real life experiences, concrete models and diagrams, oral language and symbols

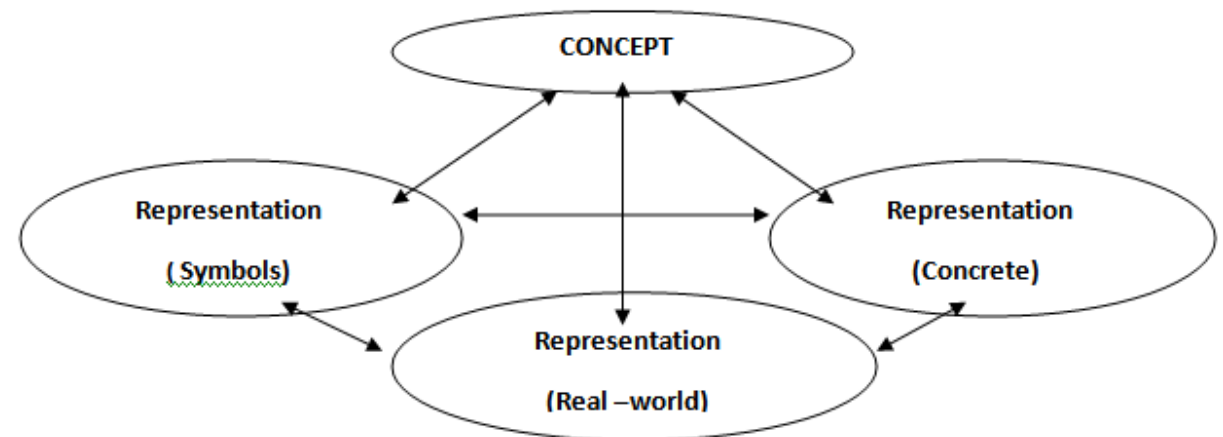

Figure 1: Conceptual Knowledge Connections in Mathematics in a Primary Classroom

Long lasting ability to the versatile use of mathematical knowledge, both procedural as well as conceptual, have been demonstrated by students who have been able to make these connections. Towsley (1989) has stated that grade four students reasoned with fractions as quantitative and not as whole numbers when doing word problems and these students were the ones who had successfully established these conceptual knowledge connections. Various educators and researchers (Cramer \& Bezuk 1991; Ellenbruch \& Payne 1978; Lesh, Post \& Behr 1987). Students without connections among real-world experiences, concrete models, diagrams, oral language and symbols lack the power of making sense of mathematics and as such are unable to relate it to the world around them.

Results and studies of related empirical researchers suggest that mathematical concepts get constructed through conceptual understanding based on the use of various kinds of representations, manipulations and communication between these representations. The more the representations, the better, the deeper and longer lasting will be the concept. Ainsworth (2008) indicated that if all information of the complex concepts get included in a single representation, then the chances are high that the representation may be misrepresent it. One representation cannot describe a mathematical concept fully and since each representation has different advantages, so the use of a variety of representations may form the core of mathematical understanding. The use of various non-traditional instructional approaches and activities in fraction teaching will help the students to make conceptual knowledge connections efficiently (Canterbury, 2007).I

The concept of "representation in connection with teaching and learning of mathematics can be given various meanings. Seeger, Voight \& Werchescio (1998) defined it as

“... representation is any kind of mental state with a specific content, a mental reproduction of a former mental state, a picture, a symbol, or sign, or symbolic tool one has to learn, a something "in place of" something else."

In the year 2000, the National Council of Teachers of Mathematics (NCTM) published the document "Principles and Standards for School Mathematics" that included "representations" and specified it as one of the key components in the curriculum that needed to be emphasized during the teaching and learning of mathematics. NCTM (2000) defined the concept of representation as "The act of capturing a mathematical concept or relationship in some form and to the form itself." This definition integrates internal and external representations. Internal representations occur in the mind in the form of cognitive models, schemas, concepts or mental objects, whereas external representations are embodiments of mathematical ideas or concepts such as symbols, tables, graphs, verbal statements and concrete materials. Goldin \& Shteingold (2001)claim that external representations are easier to use, permit visualization and are universal and that internal representations are held individually and cannot be shown to other people.

The present study has tried to investigate the role of multiple representations in making conceptual knowledge connections to clear misconceptions in fraction in $4^{\text {th }}$ grade students.

There are many models in the field of multiple representations. In the following, we look at two models that draw the theoretical framework of this study.

\subsection{Janvier's Model of Multiple Representations}

According to Janvier (1987)- a representation may be considered as a combination of three components : written symbols, real objects and mental images. He greatly emphasized the external representations and made a visual resemblance between a representation and star (Figure2) which shows the five kinds of external 
representations: Tables, Graphs, Formulation, Verbal Descriptions and Object. In Janvier's Model, the translation occurs while going from one vertex to another. Translation refers to psychological processes involved in going from one form of representation to another for example from an equation to a graph or vice versa and thus a translation always involves two forms of representations. The traditional instructional strategies should be modified in such a way that they include multiple representations as well as flexibility to use translation processes in representations (Oylum, 2004).

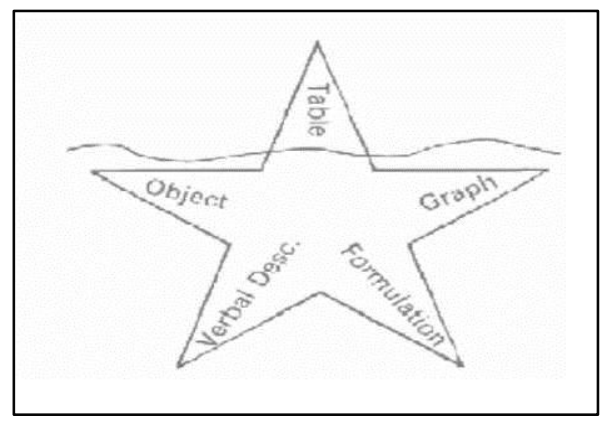

Figure 2: The visual resemblance between a representation and a star.

\subsection{Lesh's Multiple Representations Translations Model}

Lesh (1979) suggests through this model that if a student understands a mathematical idea, he should have the ability of making translations between and within modes of representations. According to Lesh, Post and Behr (1987), representations are crucial for understanding mathematical concepts. They defined representations as "external (and therefore observable) embodiments of students' internal conceptualizations." According to Lesh, et al (1987), the five modes of representations that occur in mathematical learning and problem solving are (Table 1)

\begin{tabular}{|l|l|l|}
\hline 1 & Real world situations & Knowledge is organised around real life events \\
\hline 2 & Manipulatives & $\begin{array}{l}\text { Objects that can be touched, moved, \& often stacked like fraction } \\
\text { circles, unifix cubes, etc }\end{array}$ \\
\hline 3 & Pictures & Static figural models or diagrams \\
\hline 4 & Spoken Symbols & Can be everyday language \\
\hline 5 & Written Symbols & Mathematical symbols, words, phrases \\
\hline
\end{tabular}

Table 1 : Five Types of Representation in Lesh's Translation Model

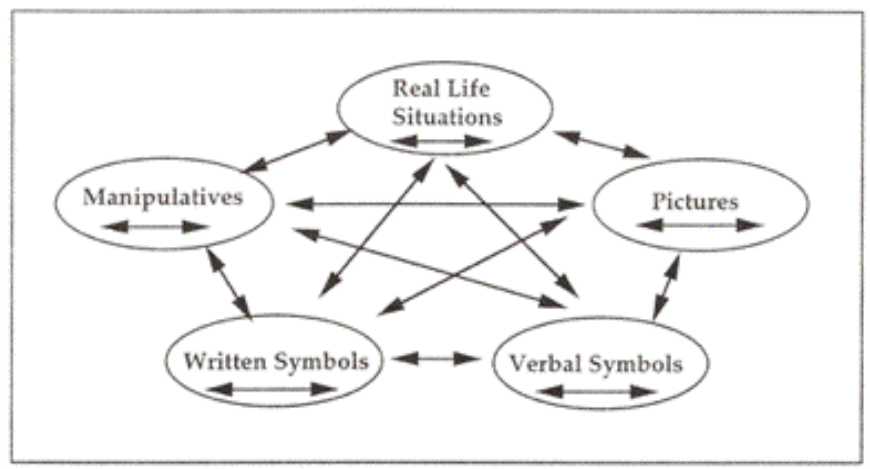

Figure 3 : Lesh's Translational Model (1979)

According to Stewart (2005) Lesh's Translation Model stresses that deep understanding of mathematical ideas get reflected in the ability to represent mathematical ideas in five different modes as well as the ability to make connections between them.

\subsection{Sample and Research Design}

\section{Methodology}

In the present study, a class of 40 students of grade 4 from a well to do private school in South Delhi was selected randomly and these 40 students were randomly distributed in two groups of 20 students each, one forming the control group and the other forming the experimental group. Fraction concepts were taught to the experimental group using an instructional program utilising multiple representations to build conceptual 
knowledge connections. The control group learned the same concepts but with a traditional approach. The teaching process took place for 6 weeks with 5 sessions of 40 minutes each per week.

Quasi-experimental research design was used. (Table 2)

Table 2 - Research Design

\begin{tabular}{lccc}
\hline Experimental Group & T1 & X & T2 \\
\hline Control Group & T1 & & T2
\end{tabular}

T1=Pre-test, $\quad \mathrm{T} 2=$ Post-test $\quad \mathrm{X}=$ Independent variable (Multi-representational instruction)

To assess the primary knowledge of the students about fraction concepts, a pre-test was conducted for both the groups and after the instructional program ended a post test was given to both the groups. The test validity and reliability ( Cronbach's Alpha $=0.995$ ) was administered for both groups. The data from both the tests were analysed using statistical software. For the interviews, based on the classroom observations and the post-test scores 5 children were randomly selected from each group. The observations and interviews were conducted keeping the following research questions in mind:

Question A: Did the approach using multiple representations lead to conceptual knowledge connections in grade 4 students?

Question B.: Did the multi-representational approach better the performance of students in solving fraction problems?

Question C: What are the origin of misconceptions of grade 4 students in fractions?

Question D: What kind of representations did children prefer in solving fraction problems?

\subsection{Instructional Approach Used}

In the control group fractions were taught by the conventional approach using different representations but discretely and separately with the teacher making no connection between these representations. But in the experimental group, for each concept introduced, an activity based on the problem was given to the students and the students were encouraged to use multiple representation and make connections between these representations. By the end of the instruction program it was hoped that the students would:

1. Demonstrate fraction number sense and operation sense by:

a) Making connections among real-world, concrete/pictorial, oral language, and symbolic representations for all four operations

b) See how the four operations are related

c) Gain insight into the effects of an operation on a pair of fractions or a fraction or a whole

d) Realise that a specific fraction amount can have multiple names

2. Be able to communicate their knowledge of fractions using written, pictorial, oral, concrete and symbolic language

3. Use various problem solving strategies for word problems such as acting out the situation with paper strips or diagrams or visualising actions on objects

4. Be confident about approaching word problems in fractions.

\subsection{Quantitative Analysis}

\section{Results}

Results of the independent $t$-tests done to investigate the difference between means of the two groups in the pre-tests indicate that between the means of the two groups (experimental and control) there is no significant difference (level of meaningful sig. $=0.41$ which is bigger than $\alpha=0.05$ ) pointing to the fact that the students of the two groups had the same level of understanding fraction concepts before the multirepresentational instruction course.

Table 3- Results of independent t-test (Pre-test)

\begin{tabular}{|l|l|l|l|l|l|l|l|l|l|}
\hline Group & $\mathrm{N}$ & Mean & $\begin{array}{l}\text { Std. } \\
\text { Deviation }\end{array}$ & Upper & Lower & $\begin{array}{l}\text { Std. Error } \\
\text { Difference }\end{array}$ & df & t & $\begin{array}{l}\text { Sig.(2 } \\
\text { tailed })\end{array}$ \\
\hline Experimental & 20 & 9.20 & 3.21 & 2.86 & -1.21 & 1.007 & 38 & 0.82 & 0.42 \\
\hline Control & 20 & 8.37 & 3.15 & & & & & \\
\hline
\end{tabular}


Making Conceptual Knowledge Connections to Clear Misconceptions in Fractions in Primary...

Table 4- Results of independent t-test (Post-test)

\begin{tabular}{|l|l|l|l|l|l|l|l|l|l|}
\hline Group & $\mathrm{N}$ & Mean & $\begin{array}{l}\text { Std. } \\
\text { Deviation }\end{array}$ & Upper & Lower & $\begin{array}{l}\text { Std. Error } \\
\text { Difference }\end{array}$ & df & $\mathrm{t}$ & $\begin{array}{l}\text { Sig.(2 } \\
\text { tailed) }\end{array}$ \\
\hline Experimental & 20 & 13.17 & 2.81 & 4.75 & 1.20 & 0.88 & 38 & 3.39 & 0.002 \\
\cline { 1 - 3 } & 20 & 10.11 & 1.74 & & & & & & \\
\end{tabular}

Results of the independent t-test to investigate the difference between means of the two groups in the post-tests (Table 4) indicate that between the means of the two groups there is a point of meaningful statistical difference (level of meaningful sig. $=0.002$ which is smaller than $\alpha=0.05$ ) and that the students of the experimental group had gained better understanding of the fraction concepts than the students in the control group.

\subsection{Qualitative Analysis}

To investigate deeper aspects of students' understanding and thinking processes, classroom observations were done by the researcher and interviews were conducted with 10 students in all, 5 from each group. During these interview sessions each student was asked a series of general questions to break the ice and given a fraction problem to solve. While the child solved the problem observations were recorded and after the completion of the problem, a series of questions was posed to the child and their answers recorded. The questions were such that they would show the thinking of the child and the kind of representations they prefer to use.

\section{Student's view on fractions in general}

The answers of the students in the control group were indicative of the difficulties they faced and that they did not find dealing with fractions easy at all. In fact they found it challenging and they could not find considerable implications of the topic in their own life. The students in the experimental group were excited and thought doing fractions was fun using fraction kits, circles and sharing pizzas and cookies. They found solving the problems easy.

\section{What students thought while solving and the kind of representations they used}

In general, the participants taught by the traditional method thought more about using the symbolic representations and calculations and if the instructions did not suggest drawing of pictures they did not use pictures. They would look for the key words in the problems instead of trying out things pictorially or drawings etc. The students in the experimental group thought of drawing pictures or stacking fraction pieces and then move on to the algebraic calculations. Some even said that they would arrive at the answer by playing around with their fraction kits and only verified the answer by the algebraic method. This helped them in asserting their answers confidently, since it helped them in recognising the correctness or incorrectness of their answers. For example in the following problem:

Reena and Shaila each ate $1 / 4$ of a cake their mother had bought. Their mother ate $1 / 2$ of the cake. How much of the cake was left over? Explain your answer in your own words.

For the participants of the control group this seemed like a difficult problem. Two of the students found it difficult to come to an answer because they got stuck with the implications of the words 'left over'. Three of the students had written the solution as

$$
\begin{aligned}
& 1 / 4+1 / 2=3 / 4, \\
& 1-3 / 4=1 / 4
\end{aligned} \quad 1 / 4 \text { of the cake is left }
$$

Two of the participants in the experimental group took out 1 piece of $1 / 4$ and one $1 / 2$ from their fraction kit and put them together but then when they tried to draw the picture with the names of the children, they could immediately figure out that both children had eaten $1 / 4$, so there would be two $1 / 4$ pieces to be put together with the $1 / 2$ piece and hence came up with the correct answer pictorially. Then they verified their answer by the algebraic method as $1 / 4+1 / 4+1 / 2=1$ whole. So nothing was left.

$$
\begin{aligned}
& \mathrm{R}=\text { Reena }=1 / 4 \\
& \mathrm{~S}=\text { Shaila }=1 / 4 \\
& \mathrm{M}=\text { Mother }=1 / 2
\end{aligned}
$$




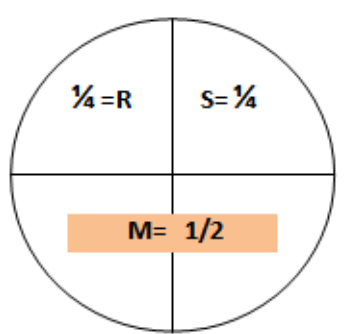

Figure 4

\subsection{Answers to research questions in the light of qualitative analysis}

Referring to research questions A \& B stated previously in the paper, the qualitative analysis from the data of interviews and classroom observations throws light upon the students of the experimental group moving closer towards understanding of the fraction concepts and using conceptual knowledge connections to better their performance in problem solving. They showed lesser errors than the students in the control group who used more of procedural knowledge and made more errors. Regarding the research question $\mathrm{C}$ the students in both the groups had many misconceptions which came to light during interviews and observations while children were hands on at the problems. After the instructional program, the students receiving the treatment showed lesser misconceptions. For example one of the misconceptions was that students associated the total number of parts/divisions showed in the figure as the denominator and the numerator as the shaded portion only, irrespective of the fact that the parts were not of equal area. When the students were asked to tell what fraction of the figure was depicted by ' $b$ ' most participants in the control group gave incorrect answer such as $1 / 5$., whereas a majority of the experimental group gave the correct answer as $1 / 4$. This is indicative of the fact that the conceptual understanding of fractions using translations led the children in the experimental group to face lesser difficulties with concepts since they had moved ahead of getting stuck with rules and procedures and had built up a good fraction sense by the handling of the manipulative material.

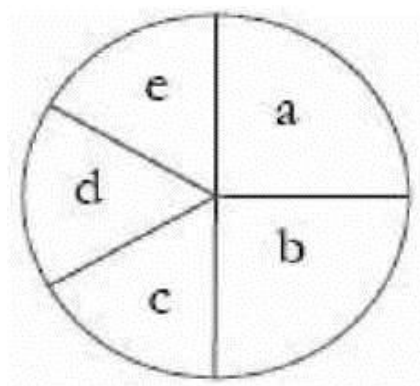

Figure 5: Posed as a part of the interview problems

Regarding the last research question D the classroom observations and the comparative data from the interviews suggests that the students exposed to the traditional approach restricted the problem solving to using only numerical representations only and hardly any pictorial or diagrammatic representations were linked to them.

During the follow-up interviews, all students having undergone multi-representational instruction program dealt with the fraction symbols as representing some quantity and did not merely manipulate the symbols without meaning. These students either used fraction circles or drew diagrams to help them solve problems or they reasoned through the solving of the problem by mentally visualising the problem.

\section{Conclusions}

The research study has documented that, compared to conventional mode of instruction, multiple representations based instruction did make a significant contribution to the performance of fourth grade students in fractions. The findings of this study indicate that using multiple representations, conceptual knowledge connections could be enhanced in a complex mathematical topic like fractions. The investigation also threw light on the types of misconceptions grade four students might have and that some of the factors that played a role in the students' difficulties and misconceptions with learning and understanding of fractions can be tackled and lessened to a great extent using the multi-representational approach. It has implications that in a traditional mathematics classroom, there is a need to encourage students to think more deeply on mathematical concepts, relate them to the real world situations around them, to avoid overemphasising 
mathematical rules and procedure and attempt problem solving using as many representations as they can at the elementary grade level to make the learning more meaningful and lasting.

\section{References}

[1]. Ainsworth, S. (2008). The educational value of multiple-representations when learning complex scientific Concepts. In J. K Gilbert, M. Reiner, and M. Nakhleh (Springer), Visualization: Theory and Practice in Science Education. Volume3, Models and Modeling in Science Education. p.196

[2]. Canterbury, S.A (2007). An investigation of conceptual knowledge: Urban African American Middle School Student' use of fraction representations and computations in performance-based tasks. (Doctoral dissertation University of Georgia, 2006), pp. 1980,215

[3]. Cramer, K., \& Bezuk, N. (1991) Multiplication of fractions: Teaching for understanding. Arithmetic Teacher 39, 34-37

[4]. Ellenbruch, L.W., \& Payne, J.N.(1978). A Teaching sequence from initial fraction concepts through ther addition of unlike fractions. In M. Suydam (Ed.), Developing Conceptual Skills (pp. 129-147). Reston, VA: National Council of Teachers of Mathematics

[5]. Goldin, G., \& Shteingold, N. (2001). Systems of representations and the development of mathematical concepts. In A.A. Cuoco, \& F.R. Curcio (Eds.), The Roles of Representations in School Mathematics (pp. 1-24). Reston:NCTM Publications

[6]. Hitt, F. (2001). Working Group on Representations and Mathematics Visualization.

[7]. Representation and Mathematics Visualization, pp 2, 3.

[8]. Janvier, C. (1987). Representations and Understanding: The notion of function as an example. In C. Janvier (Ed.) Problems of Representations in the Learning and Teaching of Mathematics . New Jersey: Lawrence Erlbaum Associates.

[9]. Lesh, R. (1979). Mathematical learning disabilities: considerations for identification, diagnosis and remediation. In R. Lesh, D. Mierkiewicz, \& M.G. Kantowski (Eds), Applied Mathematical Problem Solving. Ohio: ERIC/SMEAC

[10]. Lesh, R., Post, T., \& Behr, M.(1987). Representations and translations among representations in mathematics learning and problem solving. In C. Janvier (Ed), Problems of Representation in the teaching and Learning of Mathematics (pp. 33-40). Hillsdale, NJ:Lawrence Erlbaum Associates

[11]. National Council of Educational Research and Training ( 2008). Mathematics Sourcebook on Assessments (pp 206-225), NCERT publication . Retrieved from http://www.ncert.nic.in/html/pdf/announcement/sourcebook/ChapterVMathematics.pdf

[12]. National Council of Teachers of Mathematics, (2000). Principles and standards for school mathematics. Reston, VA: NCTM . pp . 67,206,208.

[13]. Oylum, C. A. (2004). The effects of multiple representations-based instructions on several grade students' algebra performance, attitude toward mathematics, and representation preference. $\mathrm{PhD}, 15-28$.

[14]. Seeger, F., Voight, I., \& Werchescio, V. (1998). Representations in the mathematics classroom:reflections and constructions. In F. Seeger, I. Voight, \& V. WErchescio, (Eds). The Culture of the Mathematics Classroom (pp3o8-343). Cambridge:Cambridge University Press.

[15]. Stewart, V. M. (2005). Making sense of students' understanding of fractions: An exploratory study of sixth graders' construction of fraction concepts through the use of physical referentand real world representations. (Doctoral dissertation, Florida State University, 2005), pp.37, 171-173.

[16]. Towsley, A. (1989). The use of conceptual and procedural knowledge in the learning of concepts and multiplication of fractions in grades 4 and 5. Doctoral dissertation, University of Michigan. 